\title{
Inventario de atractivos turísticos naturales y culturales de la comunidad Capirona en la parroquia de Puerto Napo, cantón Tena, provincia de Napo
}

Inventory of natural and cultural tourist attractions of Capirona community, Puerto Napo parish, Tena canton, Napo province

Shakira Lissett Salazar Mora. ${ }^{1}$, Nancy Patricia Tierra Tierra. ${ }^{2} \&$ Edison Marcelo Salas Castelo. ${ }^{3}$

Recibido: 10-05-2020 / Revisado: 15-06-2020 /Aceptado: 04-07-2020/ Publicado: 07-08-2020

\begin{abstract}
.
DOI: https://doi.org/10.33262/concienciadigital.v3i3.1.1379

Sustainable tourism delivers development opportunities for the inhabitants of a territory. The potential of the tourist activities to be established in any particular place depends on the attractions found in the area, their quality, as well as the infrastructure and services associated with these attractions. This article presents the results of the tourist natural and cultural tourist attractions of Capirona Community carried out for the Gobierno Autónomo Descentralizado Parroquial de Puerto Napo. The methodology proposed by the Ecuadorian Ministry of Tourism, 2017 was employed for the preparation of the inventory. The data collection field work was performed during 20 days in August 2019. Participatory workshops were held with inhabitants and community representatives. The results show that, in the case of cultural attractions, one of the problems is the low investment made for research, documentation, publication and transmission of cultural manifestations and representations. On the other hand, most of the natural attractions have deficiencies in terms of a lack of tourist

1 Investigadora Independiente, lissettsalazar1995@gmail.com

2 Escuela Superior Politécnica de Chimborazo, Facultad de Recursos Naturales, ntierra@espoch.edu.ec

${ }^{3}$ Escuela Superior Politécnica de Chimborazo, Facultad de Recursos Naturales, Secretaría Nacional de Ciencia, Tecnología e Innovación SENESCYT-Ecuador, esalas@espoch.edu.ec
\end{abstract}


facilities, accessibility, and services, conditions that do not allow their use for the benefit of the community.

Keywords: Tourist inventory, tourist attractions sustainable development, community tourism

\section{Resumen.}

El turismo sustentable puede presentar oportunidades de desarrollo para los habitantes de un territorio en particular. El potencial turístico depende de los atractivos que se encuentren en la zona, la calidad de los mismos, así como de la infraestructura y servicios asociados a dichos atractivos. Como colaboración con el Gobierno Autónomo Descentralizado Parroquial de Puerto Napo, se realizó inventario de atractivos turísticos naturales y culturales de la comunidad Capirona, la cual se encuentra bajo su jurisdicción. Para la elaboración del inventario se empleó la metodología propuesta por el Ministerio de Turismo del Ecuador 2017. El trabajo de campo para la recolección de datos tuvo lugar en agosto de 2019 con una duración de 20 días, durante los cuales se realizó talleres participativos con habitantes y representantes de la comunidad. Los resultados muestran que, en el caso de los atractivos culturales, uno de los problemas es la escasa inversión realizada para la investigación, documentación, publicación y transmisión de las manifestaciones y representaciones culturales. Por otro lado, los atractivos naturales en su mayoría presentan deficiencias en cuanto a la inexistencia de facilidades turísticas, accesibilidad y servicios, condiciones que no permiten un aprovechamiento en beneficio para la comunidad.

Palabras claves: Inventario turístico, atractivos turísticos, desarrollo sostenible, turismo comunitario

\section{Introducción.}

El Ecuador al albergar en su territorio pueblos milenarios, cuyas costumbres, tradiciones y cosmovisión han sobrevivido el paso del tiempo, tiene en el turismo la oportunidad de compartir este patrimonio con el mundo. Este patrimonio puede ser aprovechado responsablemente para mejorar de las condiciones de vida de los habitantes de diversos territorios por medio de una intervención turística sostenible (Salazar, Tierra, \& Salas, 2020), propiciando actividades turísticas respetuosas con medioambiente y la cultura, apoyando de esta manera su conservación a través de la concientización e interpretación de los visitantes y gestores turísticos, y que además, estas actividades turísticas presenten viabilidad económica (Linares \& Garrido, 2014; Ministerio del Ambiente, 2020). Sin embargo, hay que cuidar que la actividad turística sea compatible con los criterios de la sostenibilidad, ya que, el turismo en ocasiones puede estar excesivamente orientado al desarrollo económico (Higgins-Desbiolles, 2018). 
En este contexto, este artículo presenta el resultado de la elaboración del inventario de atractivos turísticos naturales y culturales de la comunidad Capirona en la parroquia de Puerto Napo, cantón Tena, provincia de Napo. La elaboración del presente inventario responde a la necesidad de presentar alternativas de desarrollo adecuadas para los habitantes de la comunidad quienes, junto con el gobierno parroquial, ven en el turismo una oportunidad para mejorar sus condiciones de vida, siempre teniendo en mente la sostenibilidad.

El cantón Tena goza de un gran reconocimiento turístico, debido en buena parte a su exuberante diversidad biológica, así como los numerosos atractivos naturales y culturales que posee. Este cantón ubicado en la Amazonía ecuatoriana tiene dentro de su jurisdicción 7 parroquias rurales y varias comunidades indígenas (Gobierno Autónomo Descentralizado Municipal de Tena, 2014). La comunidad Capirona, perteneciente a la Parroquia Puerto Napo, es hogar de 334 habitantes, de los cuales, el 51\% corresponde a mujeres, mientras que el $49 \%$ corresponde a hombres. A su vez, los datos por rango de edad indican que hay un $40 \%$ de niños y niñas, $17 \%$ de adolescentes, $37 \%$ de adultos y un $6 \%$ corresponde a adultos mayores (Salazar et al., 2020).

\section{Turismo.}

Existen diversos conceptos de turismo, los cuales típicamente responden a la perspectiva de la disciplina de estudio y, así mismo, a la perspectiva de la oferta y la demanda (Morillo, 2011). El turismo es un fenómeno social, cultural y económico (Organización Mundial del Turismo [OMT], 2020) que se refiere al desplazamiento de las personas de manera temporal y voluntaria (Raffino, 2020) por un período de tiempo consecutivo inferior a un año (OMT, 2020). Además, el turismo se entiende como un conjunto de actividades generadoras de bienes y servicios, los cuales de forma directa o indirecta se convierten en un soporte de actividades de negocio basadas, entre otras, en el ocio, placer o actividades profesionales que se desarrollan en lugares diferentes a los de residencia habitual de los visitantes (Guerrero \& Ramos, 2014; OMT, 2020; Raffino, 2020), y siempre y cuando el motivo de viaje sea diferente al desarrollo de actividades remuneradas en el lugar visitado (Guerrero \& Ramos, 2014). La variedad de motivos de viaje y visita de los turistas, a uno o varios lugares en particular, ha producido también una diversificación de las modalidades y tipos de turismo, cuya clasificación resulta útil al momento de planificar la oferta turística (Morillo, 2011). Consecuentemente, el sistema turístico debe trabajar por cumplir de manera específica y personalizada dichas necesidades. Así, la oferta turística, durante la travesía, brinda al visitante la posibilidad de disfrutar de numerosos paisajes, creando múltiples eventos que produzcan nuevas experiencias turísticas, por tanto, cumpliendo con expectativas, deseos, anhelos, y sobre todo con la necesidad de apreciar situaciones de vida, cultural, social, fuera de su contexto habitual corresponde (Guerrero \& Ramos, 2014). El turista entonces podrá también hacer uso, de la estructura, infraestructura y supraestructura turística, las cuales 
incrementan en todo momento su bagaje vivencial en todos los ámbitos que a éste corresponde (Guerrero \& Ramos, 2014).

El turismo con su diversidad de actividades es, en la actualidad, una fuente importante de generación de recursos. De acuerdo con el World Travel and Tourism Council [WTTC] (2020), la contribución del turismo, en el año 2019, a la economía alcanzó un 10, 3\% del PIB mundial. Además, el turismo en los últimos años ha demostrado ser uno de los sectores económicos globales que crecen con mayor rapidez, de forma continua y a su vez presenta una interesante diversificación de su oferta (OMT, 2019; WTTC, 2020).

En el caso ecuatoriano, en el año 2019, los ingresos por concepto de turismo alcanzaron los 2287,5 millones de dólares, lo cual representa un 2,2\% del PIB nacional. De la misma forma, a diciembre de 2019, unas 477382 personas se encontraban empleadas en establecimientos de alojamiento y alimentación (Ministerio de Turismo [MINTUR], 2020).

Considerando la perspectiva de satisfacer las necesidades específicas de los turistas, las actividades del turismo pueden ser clasificadas de diversas formas. Esta clasificación, típicamente conocida modalidades de turismo, ayuda a determinar la vocación y, al mismo tiempo, el potencial turístico de un territorio en particular. La Tabla 1 contiene una compilación de las definiciones de los diversos tipos o modalidades del turismo.

Tabla 1. Modalidades del turismo

\begin{tabular}{|c|c|}
\hline $\begin{array}{l}\text { Turismo de } \\
\text { Naturaleza }\end{array}$ & $\begin{array}{l}\text { Busca delimitar a un tipo de viajero más exigente, cuya principal motivación es estar en } \\
\text { contacto con la naturaleza. Principalmente desarrollado por turistas jóvenes con inquietudes } \\
\text { por el deterioro del medio ambiente y preocupados por temas como el calentamiento global, } \\
\text { el desarrollo social y el enriquecimiento cultural (Entorno Turístico, 2019) }\end{array}$ \\
\hline $\begin{array}{l}\text { Turismo de } \\
\text { salud }\end{array}$ & $\begin{array}{l}\text { Incluye al turismo médico y al de bienestar. Los turistas se desplazan en busca de } \\
\text { tratamientos para mejorar sus condiciones de vida. Dependiendo de la necesidad, estos } \\
\text { pueden ser, tratamientos médicos, cirugías, clínicas de rehabilitación, etc. Los motivos } \\
\text { principales son para este tipo de viajes son por la calidad o lo económico de los servicios } \\
\text { médicos comparados con los de su lugar de residencia habitual (Entorno Turístico, 2019). }\end{array}$ \\
\hline $\begin{array}{l}\text { Turismo } \\
\text { cultural }\end{array}$ & $\begin{array}{l}\text { Viajes que se realizan con el propósito de experimentar otras culturas y sus identidades. } \\
\text { Entre sus objetivos está el conocimiento del patrimonio cultural. En esta modalidad de } \\
\text { turismo, los turistas disfrutan de la comunicación de valores y saberes (Boncheva \& Ibáñez, } \\
2012 \text { ). }\end{array}$ \\
\hline $\begin{array}{l}\text { Turismo de } \\
\text { Aventuras }\end{array}$ & $\begin{array}{l}\text { Son las actividades físicas recreativas, que se conocen también como extremas, que } \\
\text { involucran superar retos presentados por la naturaleza. En esta se encuentran actividades } \\
\text { que provocan una alta emoción y producción de adrenalina, así como la educación y el } \\
\text { entretenimiento. Estas a su vez se dividen en tres: de agua (rafting, buceo); de tierra } \\
\text { (escalada, caminata,) y de aire (parapente) (Illescas, 2015). }\end{array}$ \\
\hline Agroturismo & $\begin{array}{l}\text { Comprende la participación del turista en actividades productivas del campo, disfrutar de } \\
\text { la naturaleza y los productos gastronómicos de la zona (Boncheva \& Ibáñez, 2012). }\end{array}$ \\
\hline Ecoturismo & $\begin{array}{l}\text { Resalta la conservación a través del turismo comprendiendo viajes ambientalmente } \\
\text { responsables y contribución a la economía de la comunidad local de los lugares de visita } \\
\text { (Boncheva \& Ibáñez, 2012). }\end{array}$ \\
\hline
\end{tabular}




\begin{tabular}{ll}
\hline $\begin{array}{l}\text { Turismo } \\
\text { Gastronómico }\end{array}$ & $\begin{array}{l}\text { El objetivo es experimentar los sabores y productos del lugar de visita. En ciertos casos, se } \\
\text { ofrecen los talleres gastronómicos enfocados en aprender, preparar y degustar la variedad } \\
\text { gastronómica (Vida Alterna, 2019). }\end{array}$ \\
\hline Etnoturismo & $\begin{array}{l}\text { Visitas turísticas a pueblos indígenas para experimentar su cultura y tradiciones. En muchos } \\
\text { casos es posible convivir con la comunidad. Los turistas que prefieren esta modalidad de } \\
\text { turismo disfrutan de las diferentes manifestaciones culturales y paisajes del ambiente rural } \\
\text { (Vida Alterna, 2019). }\end{array}$ \\
\hline Ecoarqueología & $\begin{array}{l}\text { Turismo en zonas arqueológicas donde hay evidencia de la relación que el hombre y su } \\
\text { medio ambiente han tenido desde la antigüedad. Además, tiene como uno de sus propósitos } \\
\text { rescatar la identidad cultural y promover la conservación ambiental (Vida Alterna, 2019). }\end{array}$ \\
\hline
\end{tabular}

\section{Turismo comunitario.}

Las nuevas tendencias del turismo demandan la creación de oferta que presente experiencias únicas, donde los visitantes puedan estar entre los primeros en explorar lugares exóticos; que oferzcan, tours ecológicos, los cuales tienen preferencia sobre otros. Los turistas tambien exigen experiencias locales que los acerque a la forma de vida de los residentes y compartir entre otras cosas su comida y vivencias (MINTUR, 2019). Estas nuevas tendencias en la demanda han dado pie al desarrollo de lo que hoy en dia se conoce como turismo comunitario.

A diferencia de otras formas tradicionales de hacer turismo, el turismo comunitario, que es un concepto relativamente nuevo, consiste en "un modelo de gestión de una empresa social, cuya finalidad principal no es el rendimiento económico de los accionistas, sino la generación de impactos positivos distribuidos entre todos los miembros de una comunidad" (Cabanilla, 2019, p. 20). A través del turismo comunitario, ciertas comunidades, en su mayoría rurales, ofrecen a los turistas la oportunidad de compartir sus costumbres, formas de vida y sus conocimientos ancestrales, a través de compartir con los visitantes el desarrollar sus actividades diarias (MINTUR, 2018). Algunas comunidades indígenas se han dado cuenta que con el turismo pueden generar mayores recursos y han abierto sus puertas para mostrar los atractivos de sus pueblos y de sus regiones desde una perspectiva única. Esta forma de turismo permite tener más contacto con la gente, conocer las costumbres y el modo de vida de culturas centenarias desde adentro. Son los propios pobladores los que se convierten en guías y el dinero generado con este turismo se reinvierte en proyectos para la comunidad (MINTUR , 2018).

\section{Evaluación del potencial Turístico.}

Consiste en la valoración de los recursos existentes en un lugar en particular. Durante este proceso se ejecuta un análisis minucioso con el propósito de definir y caracterizar los atributos de dichos recursos, que les permitirán definirse como viables para ser desarrollados turísticamente y, asimismo, definir qué tipo de actividades turísticas pueden ofertarse a ese destino (Covarrubias, 2015). La evaluación del potencial permite también la identificación de potencialidades turísticas y a la vez un registro completo de todos los componentes 
turísticos que debido a sus características naturales, culturales y humanas pueden considerase como recurso turístico (Viceministerio de Turismo Perú, 2006).

Por medio de la evaluación del potencial turístico se busca consolidar al territorio de cada una de sus comunidades como destinos turísticos competitivos, aprovechar los recursos naturales y culturales de forma sostenible, mismos que constituirán como herramientas eficaces para orientar la inversión pública y mejorar la calidad de vida de sus habitantes.

\section{Inventario de Atractivos Turísticos}

El inventario de atractivos turísticos es el documento que registra de manera fidedigna la realidad de los recursos, que además contiene información técnica de la situación en que estos se encuentran. Incluye una valoración del estado de elementos naturales y/o culturales, que por sus características son susceptibles de convertirse en recursos turísticos. Este documento de identificación de recursos es en sí un instrumento de gestión útil para tomar decisiones en diferentes esferas del sector turístico (Viceministerio de Turismo Perú, 2006); el cual orienta desde el inicio el reconocimiento de las prioridades para alcanzar el desarrollo turístico. Es importante resaltar que un inventario no debe ser considerado solamente como un registro de información, si no que este constituye un instrumento de planificación que debe ser renovado y corregido y su información debe ser actualizada de forma constante (MINCETUR, 2006).

Durante el proceso de levantamiento del inventario, se registran ordenadamente los factores físicos y culturales como un conjunto de atractivos, que sirven de base para elaborar productos turísticos para una región (Santander, 2016). Todo inventario deberá presentar dos características fundamentales:

- Registra fielmente la realidad y las condiciones en las que se encuentran los recursos turísticos para, a partir de esta información implementar las estrategias necesarias que contribuyan a la mejora de los recursos y el desarrollo turístico del territorio estudiado (Viceministerio de Turismo Perú, 2006).

- Es un instrumento preciso, abierto y dinámico que permita actualizar periódicamente los cambios que se produzcan en los recursos turísticos, registrando su nueva situación, así como agregar nuevos recursos identificados (Viceministerio de Turismo Perú, 2006).

\section{Atractivo turístico}

Se entiende como atractivo turístico al conjunto de elementos materiales y/o inmateriales que pueden ser convertidos en productos turísticos capaces de influir en las decisiones de la gente propiciando así un flujo de visita a un destino en particular (MINTUR , 2018). 


\section{Clasificación de los atractivos turísticos}

De acuerdo con Metodología planteada por el MINTUR del año 2017, esta clasificación está compuesta de dos categorías:

- En la categoría de atractivos naturales tenemos varios tipos como son: montañas, planicies, desiertos, ambientes lacustres, ríos, bosques, aguas subterráneas, fenómenos espeleológicos, fenómenos geológicos, costas o litorales, ambientes marinos, tierras insulares.

- En la categoría de manifestaciones culturales tenemos varios tipos como son: arquitectura, folclore, realizaciones técnicas y científicas, acontecimientos programados.

\section{Recurso turístico}

Se entiende como recurso turístico a cualquier elemento natural o cultural que presentan características que pueden ser aprovechadas para actividades turísticas, sin embargo, estos elementos aún no tienen las adecuaciones para acoger turistas (Entorno Turístico, 2019). En un sentido amplio un recurso se refiere, no solo estrictamente por su naturaleza sino también a su valoración social. También hay que considerar que todo elemento tiene el potencial de convertirse en atractivo que la consideración de este por parte de la sociedad es un primer paso para convertirse en turístico (Arnandis-i-Agramunt, 2019). En este contexto, según Covarrubias (2015), los recursos turísticos comprenden a todos los elementos naturales y culturales de un lugar que lo hacen diferente de otro. En general, todo lugar turístico posee recursos, pero son las características particulares de estos los que hacen la diferencia provocando que un sitio sea más atractivo, turísticamente hablando, que otro, impulsando una mayor demanda. Todo sitio posee recursos, pero lo esencial es que estos sean aprovechados responsablemente maximizando su beneficio. De acuerdo con Covarrubias (2015), los recursos turísticos pueden ser agrupados en varios grandes grupos:

- Naturaleza: Parques naturales o marinos, playas, lagos, miradores, etc. La mayoría de ellos dependen del sector público y necesitan protección para protegerlos de un desarrollo que podría ser dañino.

- Patrimonio histórico: Museos, sitios históricos, catedrales, ciudades monumentales, etc. Muchos de estos lugares necesitarán restauración, gestión de visitas y mantenimiento. Buena parte de estos recursos también suelen depender del gobierno.

- Manifestaciones de la cultura tradicional y moderna: Arte, gastronomía, folklore, música, arquitectura, estilo de vida, etc. A menudo, la población local no se da cuenta de las diferencias entre su cultura y la de los visitantes, y del interés que despierta. Es importante que la gente local no se sienta explotada por el turista y que se proteja la integridad de la comunidad local.

- Ciudades: Los centros gubernamentales, tales como la capital de una región o país, suelen resultar atractivos porque llevan asociados una variedad de cosas que hacer o ver. El 
turismo generado puede ser de negocios o vacacional. Las reuniones, congresos y convenciones constituyen buena parte del turismo de ciudad.

\section{Metodología.}

El presente estudio se llevó a cabo en la Comunidad Capirona, parroquia de Puerto Napo, cantón Tena, provincia de Napo. La comunidad Capirona, es hogar de 334 habitantes, de los cuales, el $51 \%$ corresponde a mujeres, mientras que el $49 \%$ corresponde a hombres. Por rango de edad la población esta conformada por un $40 \%$ de niños y niñas, $17 \%$ de adolescentes, $37 \%$ de adultos y un $6 \%$ corresponde a adultos mayores (Salazar et al., 2020).

La etapa de recolección de datos tuvo lugar en agosto de 2019, con una duración de 20 días, durante los cuales se realizó talleres participativos con habitantes y representantes de la comunidad. En algunos casos fue necesario entrevistar personalmente, en sus hogares, a miembros de la comunidad quienes no pudieron asistir y participar en los talleres. También se realizaron visitas de observación en campo. Durante la recolección de datos, con la finalidad de recabar la información ambiental y cultural necesaria para la elaboración del inventario de atractivos turísticos, se emplearon diferentes instrumentos como: cuestionarios, boletas censales, fichas ambientales, etnobotánicas y etnozoológicas.

\section{Etapas para la elaboración del inventario de atractivos turísticos}

\section{a. Levantamiento y Registro}

Durante esta etapa, se levanta, clasifica y registra objetos, lugares, acontecimientos, fenómenos y otros factores que presenten características de importancia turística. Esta fase comprende el levantamiento, procesamiento y análisis de datos. Para el registro de información se emplean fichas para registrar los datos de cada atractivo turístico.

\section{b. Clasificación}

- Recopilación de información primaria

- Verificación con Información Secundaria.

\section{c. Ponderación y Jerarquización}

En base a la información los atractivos turísticos levantados, se realizó la respectiva ponderación y jerarquización en función de un conjunto de criterios que permitieron establecer su grado en comparación con las mejores condiciones que deben poseer como atractivos turísticos. Esta etapa es de vital importancia ya que permitió identificar los atractivos con mejores condiciones para diseñar productos. También se identificó las irregularidades que presentan los recursos para proponer acciones específicas que permitan mejorar sus condiciones. 


\section{Ponderación de criterios}

La sistematización de los resultados requiere el empleo de criterios, los cuales contienen un factor de ponderación (Tabla 2). El factor de ponderación de cada criterio responde a elementos como capacidad institucional y las competencias que permiten la mejora o manejo de estos (MINTUR , 2018).

Tabla 2. Ponderación de criterios. Atractivos Naturales y Culturales

\begin{tabular}{|c|c|c|}
\hline Criterios de valoración & Descripción & Ponderación \\
\hline $\begin{array}{l}\text { A Accesibilidad y } \\
\text { conectividad }\end{array}$ & $\begin{array}{l}\text { Condiciones de accesibilidad al atractivo, ciudad o poblado } \\
\text { más cercano, además de la existencia de vías de acceso, } \\
\text { servicios de transporte y señalización. }\end{array}$ & 18 \\
\hline $\begin{array}{l}\text { B Planta turística / } \\
\text { complementarios }\end{array}$ & $\begin{array}{l}\text { Existencia de servicios de alojamiento, alimentos y bebidas, } \\
\text { agencias de viaje, guía, transporte o movilización interna, } \\
\text { facilidades turísticas y servicios complementarios a la } \\
\text { actividad turística. }\end{array}$ & 18 \\
\hline $\begin{array}{l}\text { C Estado de conservación } \\
\text { e integración sitio / } \\
\text { entorno }\end{array}$ & $\begin{array}{l}\text { Estimación de integridad de los atributos físico-ambientales } \\
\text { y socioculturales, en particular de las condiciones del } \\
\text { atractivo y su entorno. }\end{array}$ & 14 \\
\hline $\begin{array}{l}\text { D Higiene y seguridad } \\
\text { turística }\end{array}$ & $\begin{array}{l}\text { Disponibilidad de servicios básicos, gestión ambiental, } \\
\text { señalética, establecimientos de atención ciudadana en temas } \\
\text { de salud, seguridad, comunicación y amenazas naturales. }\end{array}$ & 14 \\
\hline $\begin{array}{ll}\text { E } & \text { Políticas y } \\
& \text { Regulaciones }\end{array}$ & $\begin{array}{l}\text { Consideración del atractivo dentro de la planificación } \\
\text { territorial turística y cumplimiento de regulaciones para las } \\
\text { actividades que se realizan en el atractivo. }\end{array}$ & 10 \\
\hline $\begin{array}{l}\text { F Actividades que se } \\
\text { practican en el } \\
\text { Atractivo }\end{array}$ & $\begin{array}{l}\text { Actividades de agua, aire, tierra que se practican en atractivos } \\
\text { naturales y actividades que se practican en atractivo } \\
\text { culturales. }\end{array}$ & 9 \\
\hline $\begin{array}{l}\text { G Difusión, medios de } \\
\text { promoción y } \\
\text { comercialización del } \\
\text { atractivo }\end{array}$ & $\begin{array}{l}\text { Mención del atractivo en publicaciones en revistas } \\
\text { especializadas nacionales o internacionales, así como } \\
\text { páginas web, redes sociales, prensa, televisión, entre otros. }\end{array}$ & 7 \\
\hline $\begin{array}{l}\text { H Registro de visitantes y } \\
\text { afluencia }\end{array}$ & $\begin{array}{l}\text { Registro visitantes realizado por el administrador del } \\
\text { atractivo, temporalidad de visita, procedencia del visitante, } \\
\text { frecuencia de visitantes. }\end{array}$ & 5 \\
\hline I Recursos humanos & $\begin{array}{l}\text { Número de personas y nivel de instrucción académica del } \\
\text { personal que labora en el atractivo. }\end{array}$ & 5 \\
\hline
\end{tabular}

Fuente: Metodología para Inventario de Atractivos Turísticos, MINTUR 2017; Reporte del Índice de Competitividad Turística (OMT, 2015). 


\section{Jerarquización de atractivos turísticos}

Una vez levantada la información de los atractivos, los criterios fueron expresados de forma cuantitativa con un valor sobre 100 permitiendo realizar la jerarquización empleando una escala de I a IV (Tabla 3). Los atractivos de acuerdo con la jerarquización que se le has asignado deberán responder conforme a la siguiente descripción:

Tabla 3. Rangos y jerarquización

\begin{tabular}{ccl}
\hline Rangos & Jerarquía & Descripción \\
\hline $86-100$ & IV & $\begin{array}{l}\text { Atractivo excepcional y de gran significación para el mercado turístico } \\
\text { internacional, capaz por si solo de motivar una importante corriente de } \\
\text { visitantes actual o potencial. }\end{array}$ \\
\hline $61-85$ & III & $\begin{array}{l}\text { Atractivo con rasgos excepcionales capaz de motivar por si solo o en conjunto } \\
\text { con otros atractivos contiguos, una corriente actual o potencial de visitantes } \\
\text { nacionales e internacionales. }\end{array}$ \\
\hline $36-60$ & II & $\begin{array}{l}\text { Atractivo con algún rasgo llamativo, capaz de interesar a visitantes que } \\
\text { hubiesen llegado a la zona por otras motivaciones turísticas, o de motivar } \\
\text { corrientes turísticas nacionales. }\end{array}$ \\
\hline $11-35$ & I & $\begin{array}{l}\text { Atractivo sin mérito suficiente para considerarlo al nivel de las jerarquías } \\
\text { anteriores, pero que igualmente forma parte del inventario de atractivos } \\
\text { turísticos como elementos que complementen a otros de mayor jerarquía. }\end{array}$ \\
\hline $0-10$ & Recurso &
\end{tabular}

Nota: Metodología Inventario de Atractivos Turísticos (MINTUR, 2017).

\section{Resultados}

La presente sección muestra los resultados del estudio realizado para la elaboración del inventario de atractivos turísticos de la comunidad Capirona perteneciente a la parroquia rural de Puerto Napo, cantón Tena, Provincia de Napo.

La comunidad cuenta con atractivos turísticos con potencial para el ecoturismo, agroturismo, turismo de salud, cultural, aventura y aviturismo. Sin embargo, la comunidad enfrenta factores como el desempleo, migración, contaminación ambiental, pérdida de la identidad cultural, desconocimiento del potencial turístico, desvalorización del patrimonio, analfabetismo, entre otros, los cuales tienen una incidencia negativa en su desarrollo.

Para ayudar a superar esta problemática se desarrolló la evaluación del potencial turístico misma que se realizó a partir de una organizada, amplia y consensuada planificación, con el objeto de orientar las acciones turísticas hacia el logro del desarrollo, como aportación a la conservación y/o rescate del entorno natural y con el fin de crear nuevas alternativas de 
productos turísticos que aprovechen los recursos naturales como culturales que posee el territorio, fortaleciendo así la economía local, al mismo tiempo de favorecer la integración entre visitantes y miembros de la comunidad, el disfrute de sus paisajes naturales, costumbres y tradiciones, así como, el deleite de su diversa gastronomía a base de productos locales cien por ciento orgánicos

\section{a. Registro del patrimonio cultural}

\section{Mecanismo de levantamiento de información}

Se realizó dos talleres en el espacio cubierto de la Comunidad kichwa Capirona el primer taller realizado el 29 de julio del 2019 se trató sobre la socialización del tema, se conformaron grupos para posteriores talleres y que puedan trabajar en distintas temáticas. El segundo taller se lo llevó el 10 de agosto de 2019 donde se conversó con la gente y se pudo tener información de catorce manifestaciones las cuales posteriormente fueron registradas en las fichas del MINTUR (2017), en el mismo taller se obtuvo información sobre datos de la comunidad, luego se realizó entrevistas a personas adultas para la recolección de datos y levantar más información sobre cada manifestación.

De acuerdo con la información obtenida sobre las manifestaciones, luego de sintetizar y registrar esta información se obtuvo un total de 14 manifestaciones en la comunidad Capirona, las mismas que fueron categorizadas y calificadas en los cinco ámbitos del Patrimonio Cultural Inmaterial (PCI).

En la información levantada, sintetizada y registrada en el ámbito 1 no se obtuvo ninguna manifestación, en el ámbito 2 solo se obtuvo 1 manifestación, en el ámbito 3 igualmente una manifestación, en el ámbito 4 se logró tres manifestaciones y en el ámbito 5 se registró nueve manifestaciones, las cuales se pueden observar de forma más detallada en las siguientes fichas de registro del patrimonio cultural material e inmaterial (Tabla 4).

Tabla 4. Resumen de las manifestaciones de la Comunidad Capirona

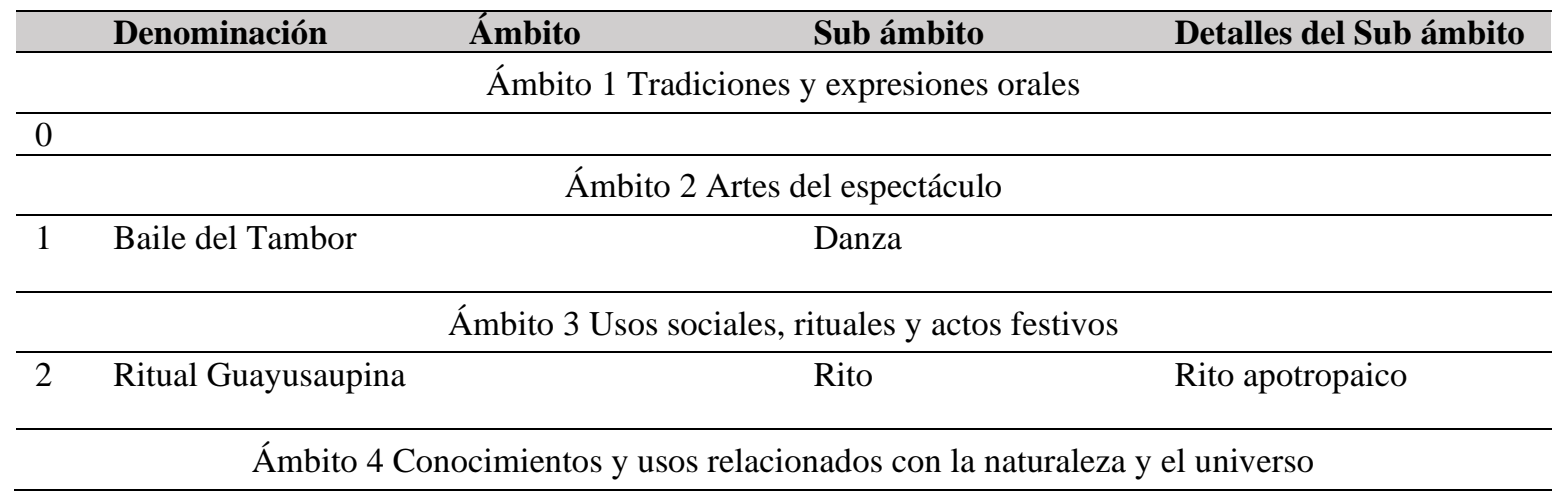


ISSN: 2600-5859

WWW.concienciadigital.org

Vol. 3, N³.1, p. 168-188, agosto, 2020

\begin{tabular}{|c|c|c|}
\hline & Denominación & Detalles del Sub ámbito \\
\hline 3 & Maito de Sapo & Gastronomía cotidiana \\
\hline 4 & Maito de Chontacuro & Gastronomía cotidiana \\
\hline 5 & Maito de Carachama & Gastronomía cotidiana \\
\hline \multicolumn{3}{|c|}{ Ámbito 5 Técnicas artesanales tradicionales } \\
\hline 6 & Elaboración de Shigras & Tejido con fibras sintéticas \\
\hline 7 & Elaboración de Atarraya & Tejido con fibras sintéticas \\
\hline 8 & Elaboración de Ashangas & Tejido con fibras naturales \\
\hline 9 & Elaboración de Tasas & Tejido con fibras naturales \\
\hline 10 & Elaboración de Bisutería de Semillas & Artesanías en semillas \\
\hline 11 & Elaboración de Bisutería de Mullos & Artesanías en mullos \\
\hline 12 & Elaboración de Pilches & Artesanía en semillas \\
\hline 13 & Elaboración de la Wami Yasa & Tejido con fibras naturales \\
\hline 14 & Elaboración de Vasijas de Barro & Alfarería \\
\hline
\end{tabular}

Fuente: equipo técnico 2019

Figura 1. Manifestaciones del patrimonio cultural inmaterial por ámbito

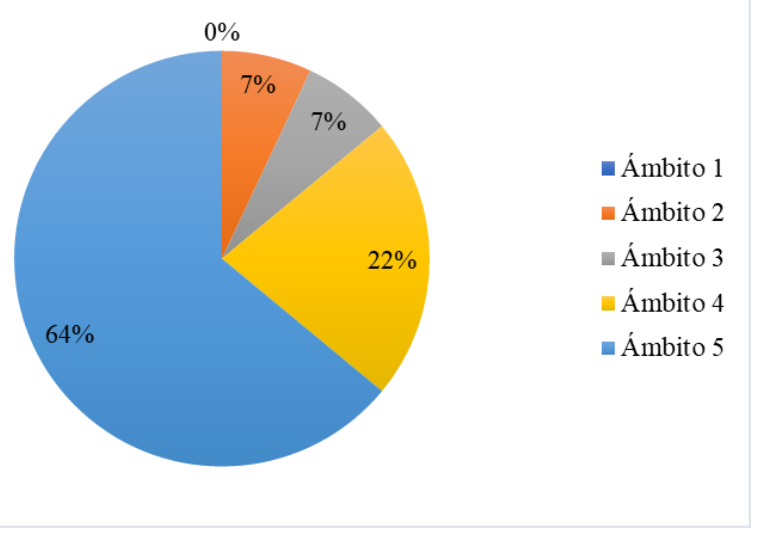

Fuente: elaboración propia

En los cinco ámbitos del patrimonio cultural inmaterial pudo identificar 14 manifestaciones predominando el ámbito 5 las técnicas artesanales tradicionales con un 64\%, seguidamente en ámbito 4 los conocimientos y usos relacionados con la naturaleza y el universo con un $22 \%$, posteriormente está el ámbito 3 los usos sociales, rituales y actos festivos con un 7\% cada uno (Figura 1).

\section{Registro del patrimonio cultural material}

De acuerdo con la información levantada mediante los talleres, no se obtuvo ninguna información por parte de la comunidad Capirona sobre manifestaciones culturales materiales.

b. Diagnóstico situacional del patrimonio cultural inmaterial de la comunidad Capirona 
Tabla 5. Matriz de valoración de las manifestaciones del Patrimonio Cultural Inmaterial

\begin{tabular}{|c|c|c|c|c|c|c|c|c|c|c|c|c|c|}
\hline \multirow[t]{2}{*}{$\mathbf{N}$} & \multirow[t]{2}{*}{ Manifestación } & \multicolumn{4}{|c|}{ 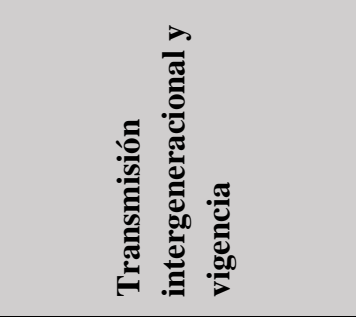 } & \multicolumn{2}{|c|}{ 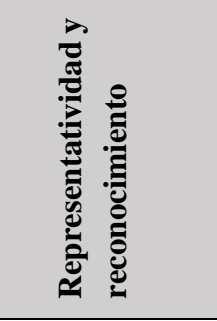 } & \multicolumn{3}{|c|}{ 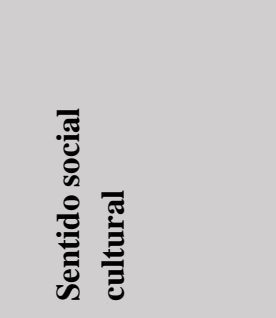 } & \multicolumn{3}{|c|}{$\begin{array}{c}\text { Estado de la } \\
\text { manifestación }\end{array}$} \\
\hline & & 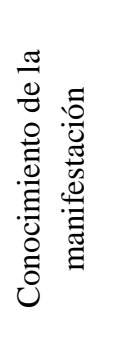 & $\begin{array}{l}\frac{7}{\pi} \\
\frac{\pi}{0} \\
0 \\
0 \\
0 \\
0 \\
0 \\
0\end{array}$ & 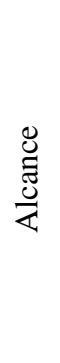 & 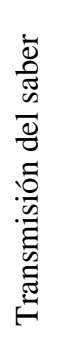 & 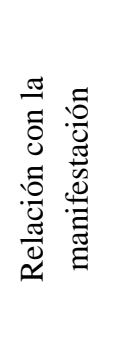 & 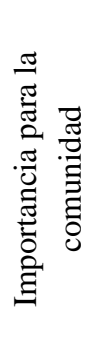 & 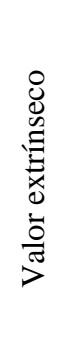 & 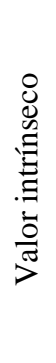 & 点 & 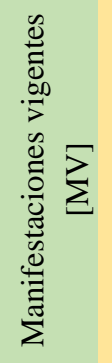 & 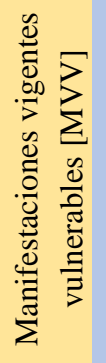 & $\sum_{\sum}^{U}$ \\
\hline 1 & $\begin{array}{ll}\text { Baile del } \\
\text { Tambor }\end{array}$ & 2 & 1 & 3 & 2 & 1 & 3 & 2 & 3 & 17 & $\mathrm{X}$ & & \\
\hline 2 & $\begin{array}{l}\text { Ritual } \\
\text { Guayusaupina }\end{array}$ & 3 & 1 & 1 & 2 & 1 & 3 & 3 & 3 & 17 & $\mathrm{X}$ & & \\
\hline 3 & Maito de Sapo & 3 & 3 & 2 & 2 & 1 & 3 & 2 & 3 & 19 & $\mathrm{X}$ & & \\
\hline 4 & $\begin{array}{l}\text { Maito de } \\
\text { Chontacuro }\end{array}$ & 3 & 3 & 2 & 2 & 1 & 3 & 2 & 3 & 19 & $X$ & & \\
\hline 5 & $\begin{array}{l}\text { Maito de } \\
\text { Carachama }\end{array}$ & 3 & 3 & 2 & 2 & 1 & 3 & 2 & 3 & 19 & $\mathrm{X}$ & & \\
\hline 6 & $\begin{array}{l}\text { Elaboración de } \\
\text { Shigras }\end{array}$ & 3 & 3 & 3 & 2 & 1 & 2 & 2 & 2 & 18 & $X$ & & \\
\hline 7 & $\begin{array}{l}\text { Elaboración de } \\
\text { la Atarraya }\end{array}$ & 3 & 2 & 3 & 2 & 1 & 3 & 2 & 3 & 19 & $X$ & & \\
\hline 8 & $\begin{array}{l}\text { Elaboración de } \\
\text { la Ashanga }\end{array}$ & 3 & 1 & 3 & 1 & 1 & 1 & 1 & 1 & 12 & & $\mathrm{X}$ & \\
\hline 9 & $\begin{array}{l}\text { Elaboración de } \\
\text { la Tasa }\end{array}$ & 3 & 1 & 3 & 1 & 1 & 1 & 1 & 1 & 12 & & $\mathrm{X}$ & \\
\hline $\begin{array}{l}1 \\
0\end{array}$ & $\begin{array}{l}\text { Elaboración de } \\
\text { la Wami Yasa }\end{array}$ & 3 & 2 & 3 & 2 & 1 & 3 & 1 & 3 & 18 & $\mathrm{X}$ & & \\
\hline $\begin{array}{l}1 \\
1\end{array}$ & $\begin{array}{l}\text { Elaboración de } \\
\text { Pilches }\end{array}$ & 3 & 1 & 3 & 2 & 1 & 2 & 1 & 2 & 15 & $\mathrm{X}$ & & \\
\hline $\begin{array}{l}1 \\
2\end{array}$ & $\begin{array}{l}\text { Bisutería de } \\
\text { Semillas }\end{array}$ & 3 & 3 & 3 & 2 & 1 & 2 & 3 & 3 & 20 & $X$ & & \\
\hline $\begin{array}{l}1 \\
3 \\
\end{array}$ & $\begin{array}{l}\text { Bisutería de } \\
\text { Mullos }\end{array}$ & 3 & 3 & 3 & 2 & 1 & 2 & 3 & 3 & 20 & $X$ & & \\
\hline $\begin{array}{l}1 \\
4 \\
\end{array}$ & $\begin{array}{ll}\text { Vasijas } & \text { de } \\
\text { Barro } & \\
\end{array}$ & 3 & 1 & 3 & 1 & 1 & 1 & 1 & 1 & 12 & & $\mathrm{X}$ & \\
\hline
\end{tabular}

Fuente: equipo técnico 2019 
Tabla 6. Estado de las manifestaciones

\begin{tabular}{llc}
\hline & \multicolumn{1}{c}{ Estado de las manifestaciones } & $\begin{array}{c}\text { Número de } \\
\text { manifestaciones }\end{array}$ \\
\hline MV & Manifestaciones vigentes & 11 \\
MVV & Manifestaciones vigentes vulnerables & 3 \\
\hline MVMC & Manifestaciones vigentes en la memoria colectiva & 0 \\
\hline
\end{tabular}

Fuente: equipo técnico 2019

Como se puede observar en la Figura 2, predominan las manifestaciones vigentes, mismas que tienen un porcentaje de 79\%, seguido de las manifestaciones vigentes vulnerables con el porcentaje restante de $21 \%$.

Figura 2. Estado de las manifestaciones

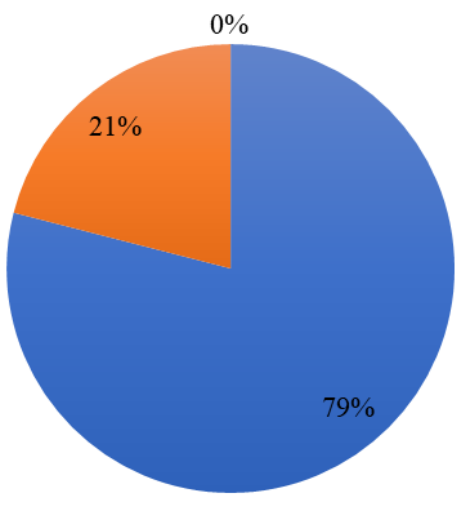

- Manifestaciones vigentes

Manifestaciones vigentes vulnerables

Manifestaciones vigentes en la memoria colectiva

Fuente: elaboración propia

\section{c. Inventario}

La Tabla 7 muestra la ubicación de los 16 atractivos turísticos encontrados en la comunidad Capirona. Los atractivos turísticos se encuentran debidamente Georreferenciados

Tabla 7. Matriz de datos georreferenciados de los atractivos turísticos

\begin{tabular}{llllccc|ccc} 
N & $\begin{array}{l}\text { Nombre del } \\
\text { Atractivo }\end{array}$ & Categoría & Tipo & Subtipo & $\begin{array}{c}\text { Jerar } \\
\text { quía }\end{array}$ & Latitud & $\begin{array}{c}\text { Ubicación UTM } \\
\text { Longitud }\end{array}$ & $\begin{array}{c}\text { Altitud } \\
\text { (msnm) }\end{array}$ \\
\hline 1 & Río Puní & Sitio Natural & Río & Río & I & 201373,20 & 9878043,5 & 345 \\
\end{tabular}




\begin{tabular}{|c|c|c|c|c|c|c|c|c|}
\hline \multirow[t]{2}{*}{$\mathbf{N}$} & \multirow{2}{*}{$\begin{array}{l}\text { Nombre del } \\
\text { Atractivo }\end{array}$} & \multirow[t]{2}{*}{ Categoría } & \multirow[t]{2}{*}{ Tipo } & \multirow[t]{2}{*}{ Subtipo } & \multirow{2}{*}{$\begin{array}{c}\text { Jerar } \\
\text { quía }\end{array}$} & \multicolumn{3}{|c|}{ Ubicación UTM } \\
\hline & & & & & & Latitud & Longitud & $\begin{array}{l}\text { Altitud } \\
\text { (msnm) }\end{array}$ \\
\hline 2 & $\begin{array}{l}\text { Bosque } \\
\text { Primario }\end{array}$ & Sitio Natural & Bosque & Húmedo Tropical & I & 202630,00 & $\begin{array}{l}9878682,0 \\
0\end{array}$ & 378 \\
\hline 3 & Guayusaupina & $\begin{array}{l}\text { Manifestación } \\
\text { Cultural }\end{array}$ & $\begin{array}{l}\text { Acervo } \\
\text { Cultural y } \\
\text { Popular }\end{array}$ & $\begin{array}{l}\text { Fiestas religiosas, } \\
\text { tradiciones y } \\
\text { creencias } \\
\text { populares }\end{array}$ & I & 201352 & 9878379 & 399 \\
\hline 4 & $\begin{array}{l}\text { Elaboración } \\
\text { de Shigras }\end{array}$ & $\begin{array}{l}\text { Manifestación } \\
\text { Cultural }\end{array}$ & $\begin{array}{l}\text { Acervo } \\
\text { Cultural y } \\
\text { Popular }\end{array}$ & Artesanías y artes & I & 201352 & 9878379 & 399 \\
\hline 5 & $\begin{array}{l}\text { Elaboración } \\
\text { de Atarrayas }\end{array}$ & $\begin{array}{l}\text { Manifestación } \\
\text { Cultural }\end{array}$ & $\begin{array}{l}\text { Acervo } \\
\text { Cultural y } \\
\text { Popular }\end{array}$ & Artesanías y artes & I & 201352 & 9878379 & 399 \\
\hline 6 & $\begin{array}{l}\text { Elaboración } \\
\text { de Ashangas }\end{array}$ & $\begin{array}{l}\text { Manifestación } \\
\text { Cultural }\end{array}$ & $\begin{array}{l}\text { Acervo } \\
\text { Cultural y } \\
\text { Popular }\end{array}$ & Artesanías y artes & I & 201352 & 9878379 & 399 \\
\hline 7 & $\begin{array}{l}\text { Elaboración } \\
\text { de Tasas }\end{array}$ & $\begin{array}{l}\text { Manifestación } \\
\text { Cultural }\end{array}$ & $\begin{array}{l}\text { Acervo } \\
\text { Cultural y } \\
\text { Popular }\end{array}$ & Artesanías y artes & I & 201352 & 9878379 & 399 \\
\hline 8 & $\begin{array}{l}\text { Elaboración } \\
\text { de Wami } \\
\text { Yasa }\end{array}$ & $\begin{array}{l}\text { Manifestación } \\
\text { Cultural }\end{array}$ & $\begin{array}{l}\text { Acervo } \\
\text { Cultural y } \\
\text { Popular }\end{array}$ & Artesanías y artes & I & 201352 & 9878379 & 399 \\
\hline 9 & $\begin{array}{l}\text { Elaboración } \\
\text { de Pilches }\end{array}$ & $\begin{array}{l}\text { Manifestación } \\
\text { Cultural }\end{array}$ & $\begin{array}{l}\text { Acervo } \\
\text { Cultural y } \\
\text { Popular }\end{array}$ & Artesanías y artes & I & 201352 & 9878379 & 399 \\
\hline 10 & $\begin{array}{l}\text { Vasijas de } \\
\text { Barro }\end{array}$ & $\begin{array}{l}\text { Manifestación } \\
\text { Cultural }\end{array}$ & $\begin{array}{l}\text { Acervo } \\
\text { Cultural y } \\
\text { Popular }\end{array}$ & Artesanías y artes & I & 201352 & 9878379 & 399 \\
\hline 11 & $\begin{array}{l}\text { Bisutería de } \\
\text { Semillas }\end{array}$ & $\begin{array}{l}\text { Manifestación } \\
\text { Cultural }\end{array}$ & $\begin{array}{l}\text { Acervo } \\
\text { Cultural y } \\
\text { Popular }\end{array}$ & Artesanías y artes & I & 201352 & 9878379 & 399 \\
\hline 12 & $\begin{array}{l}\text { Bisutería de } \\
\text { Mullos }\end{array}$ & $\begin{array}{l}\text { Manifestación } \\
\text { Cultural }\end{array}$ & $\begin{array}{l}\text { Acervo } \\
\text { Cultural y } \\
\text { Popular }\end{array}$ & Artesanías y artes & I & 201352 & 9878379 & 399 \\
\hline 13 & $\begin{array}{l}\text { Maito de } \\
\text { Sapo }\end{array}$ & $\begin{array}{l}\text { Manifestación } \\
\text { Cultural }\end{array}$ & $\begin{array}{l}\text { Acervo } \\
\text { Cultural y } \\
\text { Popular }\end{array}$ & Gastronomía & I & 201352 & 9878379 & 399 \\
\hline 14 & $\begin{array}{l}\text { Maito de } \\
\text { Chontacuro }\end{array}$ & $\begin{array}{l}\text { Manifestación } \\
\text { Cultural }\end{array}$ & $\begin{array}{l}\text { Acervo } \\
\text { Cultural y } \\
\text { Popular }\end{array}$ & Gastronomía & I & 201352 & 9878379 & 399 \\
\hline 15 & $\begin{array}{l}\text { Maito de } \\
\text { Carachama }\end{array}$ & $\begin{array}{l}\text { Manifestación } \\
\text { Cultural }\end{array}$ & $\begin{array}{l}\text { Acervo } \\
\text { Cultural y } \\
\text { Popular }\end{array}$ & Gastronomía & I & 201352 & 9878379 & 399 \\
\hline 16 & $\begin{array}{l}\text { Baile del } \\
\text { Tambor }\end{array}$ & $\begin{array}{l}\text { Manifestación } \\
\text { Cultural }\end{array}$ & $\begin{array}{l}\text { Acervo } \\
\text { Cultural y } \\
\text { Popular }\end{array}$ & Música y danza & I & 201352 & 9878379 & 399 \\
\hline
\end{tabular}

Fuente: equipo técnico 2019Análisis situacional de los atractivos turísticos 
Tabla 8. Resumen de las características del inventario

\begin{tabular}{|c|c|c|c|}
\hline \multicolumn{2}{|c|}{ Categorización } & $\begin{array}{l}\text { Cantidad de } \\
\text { atractivos }\end{array}$ & Porcentaje \\
\hline \multirow[t]{2}{*}{ Categoría } & Manifestaciones culturales & 14 & 88 \\
\hline & Sitio Natural & 2 & 12 \\
\hline TOTAL & & 16 & $100 \%$ \\
\hline \multirow[t]{3}{*}{ Tipo } & Río & 1 & 6 \\
\hline & Bosque & 1 & 6 \\
\hline & Acervo cultural y popular & 14 & 88 \\
\hline TOTAL & & 16 & $100 \%$ \\
\hline \multirow[t]{6}{*}{ Subtipo } & Río & 1 & 6 \\
\hline & Húmedo tropical & 1 & 6 \\
\hline & $\begin{array}{l}\text { Fiestas religiosas, tradiciones y } \\
\text { creencias populares }\end{array}$ & 1 & 6 \\
\hline & Artesanías y artes & 9 & 57 \\
\hline & Gastronomía & 3 & 19 \\
\hline & Música y danza & 1 & 6 \\
\hline TOTAL & & 16 & $100 \%$ \\
\hline \multirow{4}{*}{$\begin{array}{l}\text { Estado de } \\
\text { conservación del } \\
\text { atractivo }\end{array}$} & Conservado & 14 & 88 \\
\hline & Alterado & 2 & 12 \\
\hline & En proceso de deterioro & & \\
\hline & Deteriorado & & \\
\hline \multicolumn{4}{|l|}{ TOTAL } \\
\hline \multirow{4}{*}{$\begin{array}{l}\text { Estado de } \\
\text { conservación del } \\
\text { entorno }\end{array}$} & Conservado & 16 & $100 \%$ \\
\hline & Alterado & & \\
\hline & En proceso de deterioro & & \\
\hline & Deteriorado & & \\
\hline \multicolumn{4}{|l|}{ TOTAL } \\
\hline \multirow[t]{4}{*}{ Jerarquía } & I & 16 & $100 \%$ \\
\hline & II & & \\
\hline & III & & \\
\hline & IV & & \\
\hline TOTAL & & 16 & $100 \%$ \\
\hline
\end{tabular}

Fuente: equipo técnico 2019

En la jurisdicción de la comunidad Capirona se registraron 16 atractivos turísticos de los cuales: el $12 \%$ corresponde a los atractivos naturales y el $88 \%$ restante a manifestaciones culturales. En función de su tipología se evidencia una mayor concentración de atractivos vinculados con las manifestaciones culturales en lo que respecta al acervo cultural y popular con un $88 \%$ lo cual se tiene artesanías, artes, gastronomía y danza. Mientras que los sitios naturales solo se tienen dos el Río Puní y el Bosque Primario.

En relación con el estado de conservación de los atractivos a septiembre del año 2019: el $88 \%$ se encuentran conservados y el $12 \%$ poco alterado; mientras que el entorno de estos, en su mayoría se encuentran conservados. Las manifestaciones culturales de tipo inmaterial son 
las que registran un grado de conservación ya que la comunidad Kichwa Capirona mantiene vigente sus tradiciones como es su alimento e utensilios del día a día, esto se debe a que la transmisión de saberes de la cultura popular ya que ellos conocen su importancia de aprendizaje para las generaciones actuales, uno de las falencias que se pueden encontrar es la escasa inversión realizada para la investigación, documentación, publicación y transmisión de las manifestaciones y representaciones culturales.

En el caso de los atractivos naturales la mayoría presenta deficiencias en cuanto a facilidades turísticas, accesibilidad y servicios, condiciones que no permiten un aprovechamiento en beneficio para la comunidad sumado esto con manifestaciones culturales.

Los recursos turísticos en un $100 \%$ no han sido difundidos a nivel local, es por ello la necesidad de aprovechar sus recursos para dar a conocer a nivel nacional e internacional y que formen parte de la oferta turística de tour operadoras o agencias de viajes que visitan la provincia de Napo. Los atractivos turísticos naturales son de propiedad comunal lo cual implica que se deben insertar en el proceso de fortalecimiento del turismo a los pobladores de la comunidad para garantizar el buen desarrollo de las actividades en la operación.

En relación con las actividades turísticas, se debe implementar y proveer de todo el equipamiento necesario, ya que los recursos tienen un potencial alto y además de ser zonas conservadas en las cuales se pueden realizar una serie de actividades como: caminatas, aviturismo, ecoturismo, turismo de naturaleza, interpretación ambiental y cultural, turismo de aventura (paseo en canoa), turismo medicinal, pesca deportiva, convivencia comunitaria.

En cuanto a la jerarquía que alcanzan los atractivos, 100\% son de jerarquía I, quedándose solo como recurso por la falta de la infraestructura, servicios básicos y actividades a ofrecer. En función del análisis de los atractivos turísticos, el turismo se debe operar sosteniblemente, procurando su adecuado aprovechamiento para que se constituya en una actividad económica rentable, basada en los ejes de la sostenibilidad (ambientalmente responsable, socialmente justo y económicamente rentable). En tal virtud y en concomitancia con lo establecido en la planificación turística a nivel nacional, en la comunidad se pueden desarrollar las líneas de productos turísticos detalladas en la Tabla 9.

Tabla 9. Líneas de productos turísticos priorizados en función de la potencialidad del territorio

\begin{tabular}{|c|c|c|c|c|}
\hline & $\begin{array}{l}\text { Línea de } \\
\text { producto }\end{array}$ & & Variedad de producto específico & Lugar / atractivo \\
\hline 1. & $\begin{array}{l}\text { Turismo } \\
\text { deportes } \\
\text { aventura }\end{array}$ & $\begin{array}{r}\text { de } \\
y\end{array}$ & $\begin{array}{l}\text { - Deportes terrestres (caminatas y senderismo) } \\
\text { - Deportes fluviales (paseo en canoa, pesca } \\
\text { deportiva) }\end{array}$ & $\begin{array}{ll}\text { - } & \text { Río Puní } \\
\text { - } & \text { Bosque Primario }\end{array}$ \\
\hline 2. & $\begin{array}{l}\text { Ecoturismo } \\
\text { turismo } \\
\text { naturaleza }\end{array}$ & $\begin{array}{r}\mathrm{y} \\
\mathrm{de}\end{array}$ & $\begin{array}{l}\text { - Observación de flora y fauna } \\
\text { - Científico, académico, voluntario y } \\
\text { educativo (CAVE) }\end{array}$ & $\begin{array}{l}\text { - } \quad \text { Río Puní } \\
\text { - } \quad \text { Bosque Primario }\end{array}$ \\
\hline
\end{tabular}


ISSN: 2600-5859

\begin{tabular}{|c|c|c|c|}
\hline & $\begin{array}{l}\text { Línea de } \\
\text { producto }\end{array}$ & Variedad de producto específico & Lugar / atractivo \\
\hline 3. & $\begin{array}{l}\text { Turismo } \\
\text { cultural }\end{array}$ & $\begin{array}{l}\text { - Centros artesanales } \\
\text { - Centros culturales } \\
\text { - Gastronomía }\end{array}$ & $\begin{array}{l}\text { - } \quad \text { Baile del Tambor } \\
\text { - } \text { Maito de Sapo, Chontacuro y } \\
\text { - } \quad \text { Artesanías Vasijas de Barro } \\
\text { - } \quad \text { Bisutería de Semillas y Mullos } \\
\text { - Elaboración de pilches, shigras, } \\
\text { ashangas, tasas. }\end{array}$ \\
\hline 4. & $\begin{array}{l}\text { Turismo } \\
\text { comunitario }\end{array}$ & - Turismo comunitario & - Comunidad Kichwa Capirona \\
\hline 5. & $\begin{array}{l}\text { Turismo de } \\
\text { salud }\end{array}$ & $\begin{array}{l}\text { - } \text { Medicina ancestral } \\
\text { - SPA's } \\
\text { - } \quad \text { Centro de relajación y terapias alternativas } \\
\text { basado en saberes y rituales comunitarios } \\
\text { - } \quad \text { Tratamientos con plantas medicinales } \\
\text { - } \quad \text { Rituales de sanación } \\
\text { - } \text { Masajes de relajación } \\
\text { - } \quad \text { Meditación } \\
\text { - } \quad \text { Experiencia vivencial } \\
\text { - } \quad \text { Uso de plantas medicinales } \\
\text { - } \quad \text { Trail running por la selva } \\
\text { - } \quad \text { Paseos en canoa } \\
\text { - } \quad \text { Área de camping } \\
\text { - } \quad \text { Piscinas naturales }\end{array}$ & $\begin{array}{ll}\text { - } & \text { Variedad de plantas } \\
\text { medicinales } \\
\text { - } & \text { Uso del cacao y café } \\
\text { - } & \text { Ritual de la Guayusaupina } \\
\text { - } & \text { Ritual de la Ayahuasca }\end{array}$ \\
\hline
\end{tabular}

Fuente: equipo técnico 2019

\section{Conclusiones.}

- El inventario de atractivos turísticos naturales y culturales realizado en la comunidad Capirona dio como resultado 16 atractivos de los cuales el 12\% corresponde a atractivos naturales y el $88 \%$ restante a manifestaciones culturales. En función de su tipología se evidencia una mayor concentración de atractivos vinculados con las manifestaciones culturales en lo que respecta al acervo cultural y popular así se tienen artesanías, artes, gastronomía y danza, mientras que los sitios naturales solo existen dos el Río Puní y el Bosque Primario. Mismos que se encuentran conservados en un $88 \%$ y en un $12 \%$ poco alterado; la transmisión de saberes de la cultura popular de generaciones en generación ha permitido la concentración de atractivos vinculados con las manifestaciones culturales, sin embargo, una de las falencias que se pueden encontrar es la escasa inversión realizada para la investigación, documentación, publicación y transmisión de las manifestaciones y representaciones culturales. En el caso de los atractivos naturales la mayoría presenta deficiencias en cuanto a facilidades turísticas, accesibilidad y servicios, así como también la falta de difusión a nivel local condiciones que no permiten un aprovechamiento en beneficio para la comunidad, lo cual dota de una jerarquía I al 100\% de los atractivos catalogándolos como recursos por la falta de infraestructura, servicios básicos y actividades a ofrecer. 
- Agradecimiento: Agradecemos a las Señoritas Johanna Villa Ochoa y Andrea Riera Guamán, quienes formaron parte del equipo técnico de campo encargado de la recolección de datos que hicieron posible este trabajo.

\section{Referencias bibliográficas.}

Arnandis-i-Agramunt, R. (2019). ¿Qué es un recurso turístico? Un análisis Delphi a la Academia Hispana. Cuadernos de Turismo, 43, 39-68. doi:10.6018/turismo.43.02

Boncheva, A. I., \& Ibáñez, R. (2012). Medio ambiente y política turística en México Tomo I: Ecología, biodiversidad y desarrollo turístico: Instituto Nacional de Ecología.

Cabanilla, E. (2019). El turismo comunitario en el Ecuador: evolución, problemática y desafios (M. Fernández \& G. Vega Eds.). Quito Ecuador: Universidad Internacional del Ecuador.

Covarrubias, R. (2015). Evaluación del potencial en municipios turísticos a través de metodologías participativas. In Eumed.com Eciclopedia Virtual (Ed.). Retrieved from https://www.eumed.net/libros-gratis/2015/1433/potencial-turistico.htm

Entorno Turístico. (2019). Hablemos de Turismo ¿Cuáles son los tipos de turismo que existen? Retrieved from https://www.entornoturistico.com/cuales-son-los-tipos-deturismo-que-existen/

Gobierno Autónomo Descentralizado Municipal de Tena. (2014). Actualización plan de desarrollo y ordenamiento territorial; diagnóstico. Retrieved from https://www.tena.gob.ec/index.php/tena/plan-de-desarrollo\#

Guerrero, P. E., \& Ramos, J. R. (2014). Introducción al turismo. México: Grupo Editorial Patria.

Higgins-Desbiolles, F. (2018). Sustainable tourism: Sustaining tourism or something more? Tourism Management Perspectives, 25, 157-160. doi:https://doi.org/10.1016/j.tmp.2017.11.017

Illescas, L. A. (2015). Recursos turísticos. Machala, Ecuador: Ediciones UTMACH.

Linares, H. L., \& Garrido, G. M. (2014). Del desarrollo turístico sostenible al desarrollo local. Su comportamiento complejo. PASOS Revista de Turismo y Patrimonio Cultural, 12(2), 453-466.

Ministerio de Turismo. (2017). Guía metodológica para la jerarquización de atractivos y generación de espacios turísticos del Ecuador. Retrieved from https://servicios.turismo.gob.ec/descargas/InventarioAtractivosTuristicos/Parte1_Gu iaMetodologicaInventarioGeneracionEspacioTuristico2017_2daEd.pdf

Ministerio de Turismo. (2018). Turismo Comunitario en Ecuador. Retrieved from https://vivecuador.com/html2/esp/turismo_comunitario.htm

Ministerio de Turismo. (2019). Informe de Tendencias globales en Consumo, Tecnología y Turismo 2019. Retrieved from https://servicios.turismo.gob.ec/descargas/Turismocifras/Publicaciones/Tendencias/2019/TENDENCIAS-DE-TURISMO-2019.pdf

Ministerio de Turismo. (2020). Turismo en Cifras. Retrieved from https://servicios.turismo.gob.ec/turismo-cifras

Ministerio del Ambiente. (2020). Turismo Sostenible. Sistema Nacional de Áreas Protegidas del Ecuador. Retrieved from http://areasprotegidas.ambiente.gob.ec/es/content/turismo- 
sostenible\#: :text=El\%20turismo\%20sostenible\%20es\%20el,ambiental\%20a\%20lo s\%20visitantes\%20y

Morillo, M. (2011). Turismo y producto turístico. Evolución, conceptos, componentes y clasificación. Visión gerencial(1), 135-158.

Organización Mundial del Turismo. (2019). Panorama del Turismo Internacional. Retrieved from https://www.e-unwto.org/doi/pdf/10.18111/9789284421237

Organización Mundial del Turismo. (2020). Glosario de términos de turismo. Retrieved from https://www.unwto.org/es/glosario-terminos-turisticos

Raffino, M. E. (2020). Turismo. Retrieved from https://concepto.de/turismo/

Salazar, S. L., Tierra, N. P., \& Salas, E. M. (2020). Diagnóstico situacional de la comunidad Capirona, parroquia Puerto Napo, cantón Tena, provincia de Napo, previo a la elaboración del inventario de atractivos turísticos. Ciencia Digital, 4(3), 355-377. Retrieved

from http://cienciadigital.org/revistacienciadigital2/index.php/CienciaDigital/article/view/ 1360

Santander, Y. A. (2016). El inventario turístico como herramienta de desarrollo turístico (Santander, Colombia). Retrieved from https://www.monografias.com/trabajos105/elaboracion-del-inventario-turisticocomo-herramienta-desarrollo-turistico/elaboracion-del-inventario-turistico-comoherramienta-desarrollo-turistico.shtml

Viceministerio de Turismo Perú. Dirección Nacional de Desarrollo Turístico. Dirección de Desarrollo del Producto Turístico. (2006). Manual para la formulación del inventario de recursos turísticos a nivel nacional. Retrieved from http://www.ucipfg.com/Repositorio/MGTS/MGTS15/MGTSV1507/semana3/LS3.5.pdf

Vida Alterna. (2019). Modalidades del Turismo Rural. Retrieved from http://www.elclima.com.mx/modalidades_del_turismo_rural.htm

World Travel and Tourism Council. (2020). Travel and tourism global economic impact \& trends 2020. Retrieved from https://wttc.org/Research/EconomicImpact/moduleId/1445/itemId/91/controller/DownloadRequest/action/QuickDownl oad

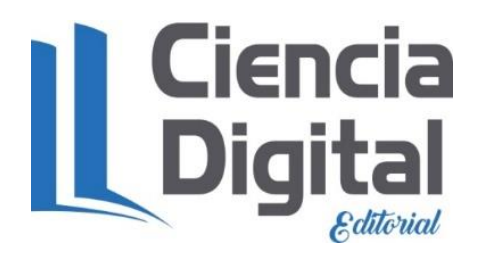


PARA CITAR EL ARTÍCULO INDEXADO.

Salazar Mora, S. L., Tierra Tierra, N. P., \& Salas Castelo, E. M. (2020). Inventario de atractivos turísticos naturales y culturales de la comunidad Capirona en la parroquia de Puerto Napo, cantón Tena, provincia de Napo . ConcienciaDigital, 3(3.1), 168-188. https://doi.org/10.33262/concienciadigital.v3i3.1.1379

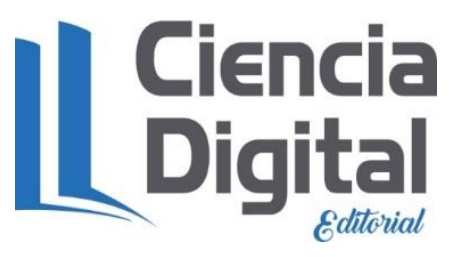

El artículo que se publica es de exclusiva responsabilidad de los autores y no necesariamente reflejan el pensamiento de la Revista Conciencia Digital.

El artículo queda en propiedad de la revista y, por tanto, su publicación parcial y/o total en otro medio tiene que ser autorizado por el director de la Revista Conciencia Digital.
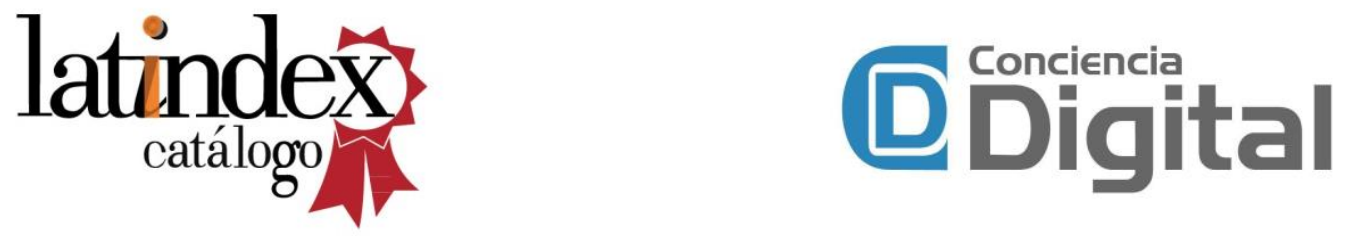